University of Nebraska - Lincoln

DigitalCommons@University of Nebraska - Lincoln

Biochemistry -- Faculty Publications

Biochemistry, Department of

2007

\title{
Arabidopsis thaliana GH3.9 influences primary root growth
}

Sadaf Khan

University of Nebraska - Lincoln

Julie M. Stone

University of Nebraska-Lincoln, jstone2@unl.edu

Follow this and additional works at: https://digitalcommons.unl.edu/biochemfacpub

Part of the Biochemistry, Biophysics, and Structural Biology Commons

Khan, Sadaf and Stone, Julie M., "Arabidopsis thaliana GH3.9 influences primary root growth" (2007). Biochemistry -- Faculty Publications. 57.

https://digitalcommons.unl.edu/biochemfacpub/57

This Article is brought to you for free and open access by the Biochemistry, Department of at DigitalCommons@University of Nebraska - Lincoln. It has been accepted for inclusion in Biochemistry -- Faculty Publications by an authorized administrator of DigitalCommons@University of Nebraska - Lincoln. 
Published in Planta: An International Journal of Plant Biology 226 (2007), pp.21-34; doi: 10.1007/s00425-006-0462-2

Copyright (C 2007 Springer-Verlag. Used by permission.

Submitted November 8, 2006; accepted December 9, 2006; published online January 11, 2007.

\title{
Arabidopsis thaliana GH3.9 influences primary root growth
}

\author{
Sadaf Khan and Julie M. Stone \\ Department of Biochemistry, Plant Science Initiative, University of Nebraska-Lincoln, \\ N230 Beadle Center, 1901 Vine Street, Lincoln, NE 68588-0664, USA \\ Corresponding author - Julie M. Stone, email jstone2@unl.edu
}

\begin{abstract}
Auxins regulate a complex signal transduction network to direct plant development. Auxin-responsive genes fit into three major classes: the so-called auxin/indole3-acetic acid (Aux/IAA), the GH3, and the small auxinup RNA (SAUR) gene families. The 20-member Arabidopsis thaliana GH3 gene family has been subdivided into three groups. In vitro studies have shown that most Group II members function as IAA-amido synthetases to conjugate amino acids to the plant hormone auxin. Here we report the role of a previously uncharacterized GH3 gene family member, GH3.9, in root growth. Unlike most other Group II family members, GH3.9 expression was repressed by low concentrations of exogenous IAA in seedlings. Transgenic plants harboring a GH3.9 promoter::reporter gene construct indicate that GH3.9 is expressed in the root-hypocotyl junction, leaves and the shoot apical meristem of young seedlings, in mature embryos, and in the root vascular tissue. Expression was also observed in lateral root tips when seedlings were treated with exogenous IAA. Inverse PCR was used to identify an activation tagged T-DNA insertion in chromosome 2 near the 5'UTR region of At2g47750 (GH3.9). Plants homozygous for the T-DNA insertion (gh3.9-1 mutants) had reduced GH3.9 expression, no obvious effects on apical dominance or leaf morphology, greater primary root length, and increased sensitivity to indole-3-acetic acid (IAA)-mediated root growth inhibition. Additional T-DNA insertion alleles and transgenic plants with reduced GH3.9 transcript levels due to RNA-interference (RNAi) also showed these same phe-
\end{abstract}

notypes. Our results provide new information on the function of GH3.9 in roots where it is likely to control auxin activity through amino acid conjugation.

Keywords: auxin, plant hormones, primary root growth, T-DNA insertion mutant

$\begin{array}{ll}\text { Abbreviations: } \\ \text { AuxRE } & \text { Auxin-responsive element } \\ \text { GUS } & \beta \text {-Glucuronidase } \\ \text { IAA } & \text { Indole-3-acetic acid } \\ \text { MeJA } & \text { Methyl jasmonate } \\ \text { RNAi } & \text { RNA interference } \\ \text { SAUR } & \text { Small auxin up RNA } \\ \text { UTR } & \text { Untranslated region } \\ \text { X-Gluc } & \text { 5-Bromo-4-chloro-3-indolyl- } \beta \text {-D-glucopyranoside }\end{array}$

\section{Introduction}

Plant development is influenced by endogenous factors such as plant hormones, and external factors such as intensity and quality of light, and water and nutrient availability. Plant hormone biosynthesis, degradation, redistribution, and conjugation to other molecules facilitate plants' adaptation to these various environmental conditions. A more complete understanding of the complex interplay between the major phytohormones and their effects on plant development is greatly needed.

Auxins are a group of plant hormones that govern key processes such as root and shoot morphology, cell 
division, cell proliferation, gravitropism, and phototropism (Woodward and Bartel 2005). Therefore the expression of many genes is regulated by these phytohormones (Goda et al. 2004). Auxin-responsive genes have been divided into three major classes: the so-called auxin/indoleacetic acid $(A u x / I A A)$, the GH3, and the small auxin-up RNA (SAUR) gene families (Guilfoyle et al. 1998; Liscum and Reed 2002). The first member of the GH3 gene family to be identified was isolated from soybean and shown to be specifically up-regulated by auxin (Hagen and Guilfoyle 1985, 2002; Hagen et al. 1991). The Arabidopsis thaliana GH3 gene family is composed of 20 members that encode proteins capable of conjugating plant hormones such as auxin, jasmonic acid, and salicylic acid to amino acids. Accumulating evidence indicates that GH3 family members function to regulate levels of biologically active hormones through amino acid conjugation, thereby targeting them for degradation/storage in the case of auxins and activating them in the case of jasmonates (Staswick et al. 2002, 2005). Based on their functions and sequence similarities the GH3 family members have been subdivided into three groups: I-III. In A. thaliana there are two Group I genes, JAR1/FIN219 and DFL2 (Hsieh et al. 2000; Staswick et al. 2002; Takase et al. 2003), eight Group II genes, including YDK1 and DFL1 (Nakazawa et al. 2001; Takase et al. 2004), and 10 Group III genes (Staswick et al. 2005). GH3 homologues are found in other plant species. The recently classified rice GH3 gene family has members corresponding to Groups I and II, but Group III members were not reported (Jain et al. 2006; Terol et al. 2006). The GH3 families have not been extensively studied in species other than rice and Arabidopsis.

The A. thaliana Group I member JAR1 (GH3.11) encodes a protein that conjugates methyl jasmonate (MeJA) to amino acids (Staswick and Tiryaki 2004). Those Group II members that have been tested for activity are indole-3-acetic acid (IAA) amido synthetases, capable of conjugating amino acids to the auxin IAA (Staswick et al. 2002, 2005). This conjugation of IAA to amino acids or other small molecules is vital for the maintenance of appropriate free (active) IAA levels in plants (Normanly and Bartel 1999; Woodward and Bartel 2005). The Group II members are named GH3.1, GH3.2, GH3.3, GH3.4, GH3.5, GH3.6, GH3.9, and GH3.17 (Hagen and Guilfoyle 2002; Staswick et al. 2005). The biochemical activities of proteins encoded by the 10 Group III genes are as yet unknown.

With some notable exceptions, the physiological roles of the GH3 family members remain a mystery. The physiological functions of only a few Group II mem- bers have been reported in the literature, perhaps as a result of genetic redundancy, or the subtlety of phenotypes associated with altered expression of these genes. Even though Group II family members might act similarly at the biochemical level, differential expression could account for the complex variation in phenotypes described (see below).

The dominant activation-tagged T-DNA insertion mutants $d f l 1-D$ and $y d k 1-D$, with insertions in the promoters of the GH3.6 and GH3.2 genes, respectively, were identified in mutant screens for altered hypocotyl elongation under varying light regimes. While uncovered in a similar mutant screen, the mutants are phenotypically distinct. The $d f l 1-D$ mutant had short hypocotyls under all light conditions tested but displayed normal etiolated seedling morphology in darkness (Nakazawa et al. 2001). The $y d k 1-D$ mutant also exhibited short hypocotyls in light but in darkness as well. In addition, the plants showed epinastic and small rosette leaves with reduced apical dominance, and short primary root lengths (Takase et al. 2004). The $y d k 1-D$ mutant had shorter roots than wild type at all auxin concentrations tested, but no significant difference in sensitivity to auxin-mediated root growth inhibition (Takase et al. 2004). In contrast, the dominant $d f l 1-D$ mutant was resistant to IAA-mediated root growth inhibition compared to wild type, and did not display a short-root phenotype (Nakazawa et al. 2001; Staswick et al. 2005). Thus, these two dominant mutations, which over express closely related GH3 Group II-family members, display distinctly different phenotypes.

Loss-of-function mutations in GH3 Group II-family members have also been reported. A putative knockout mutation in GH3.2 (YDK1) showed no obvious hypocotyl or root phenotypes (Takase et al. 2004). Plants homozygous for T-DNA insertions in GH3.1, GH3.2 (YDK1), GH3.5 (AtGH3a), and GH3.17 did not show significant differences in root growth rates, but did display altered IAA sensitivity in root inhibition assays. The gh3.1-1, gh3.17-1, and gh3.5-1 mutants all showed increased IAA sensitivity compared to wild-type controls, whereas the enhanced sensitivity of the gh3.2-1 mutant was small compared to the others (Staswick et al. 2005). These observations, i.e., enhanced IAA sensitivity in loss-of-function mutants and resistance in a gainof-function mutant $(d f l 1-D)$, are consistent with the supposition that most Group II GH3 members function by conjugating auxins to amino acids, thereby reducing free (active) auxin pools. If these Group II GH3 genes have overlapping functions, then the phenotypic variation observed in different mutants might be explained by differences in either tissue specificities and/or phyto- 
hormone regulation (i.e., inducibility by auxin or other hormones).

We have investigated the physiological roles of a previously uncharacterized GH3 gene, Group II member GH3.9. A T-DNA insertion was found in chromosome 2 near the 5'UTR region of At2g47750 (GH3.9). Plants homozygous for the T-DNA insertion, additional T-DNA insertion alleles, and transgenic plants with reduced GH3.9 expression due to RNA-interference displayed greater primary root length and showed increased sensitivity to auxin-mediated root growth inhibition in seedlings. Unlike several other Group II-family members, GH3.9 is not auxin-inducible in seedlings, and reduced GH3.9 expression does not result in defects in apical dominance or altered leaf morphology. Our results provide new information on the physiological role of an additional Group II GH3 family member.

\section{Materials and methods}

\section{Plant materials, growth conditions, genetic analyses, and hormone treatments}

All genotypes were in the A. thaliana Columbia (Col) ecotype background. The gh3.9-1 mutant was isolated from seed pools (CS21195) of plants transformed with pSKI015 activation tagging vector (Weigel et al. 2000), and T-DNA insertion lines SALK_005057, SALK_005056, and WiscDsLox419D07 (http://www.signal.salk.edu ) were obtained from the Arabidopsis Biological Resource Center (ABRC, OHIO State University, OH, USA). Dr. Paul E. Staswick (University of Nebraska-Lincoln, Lincoln, NE, USA) kindly provided gh3.17-1 and jar1-1 mutant seeds.

For plate-based assays, seeds were surface-sterilized in $3 \%$ sodium hypochlorite and $0.02 \%(\mathrm{v} / \mathrm{v})$ Tween-20 for $15 \mathrm{~min}$, washed several times with sterile water, incubated at $4^{\circ} \mathrm{C}$ for one day in $0.1 \%$ agarose, and sown on Murashige-Skoog (MS) media plates supplemented with $2 \%$ sucrose and $0.6 \%$ phytagar (Gibco-BRL, Gaithersburg, MD, USA) plus or minus various supplements. For root growth phenotypic analyses plates were incubated vertically in a growth chamber (Percival AR36L; Percival, Perry, IA, USA) at $22^{\circ} \mathrm{C}, 70 \% \mathrm{RH}$ and $\sim 130 \mu \mathrm{E} \mathrm{m}^{-2} \mathrm{~s}^{-1}$ under cool white fluorescent lights supplemented with incandescent lamps with a $12 \mathrm{~h}$ photoperiod. Auxin sensitivity assays were performed on plates supplemented with $5 \mu \mathrm{M}$ indole-3-acetic acid (IAA, No. 102037, ICN Biochemicals, Cleveland, OH, USA) as described (Tiryaki and Staswick 2002). Jasmonate sensitivity assays were performed on plates sup- plemented with $10 \mu \mathrm{M}$ methyl jasmonate (MeJA, No. 392707, Sigma-Aldrich, Milwaukee, WI, USA) as described (Staswick et al. 1992). Primary root length was determined (in $\mathrm{mm}$ ) daily after emergence of the root for a period of 10 days using calipers.

For seed collection, genetic crosses and RNA and DNA isolation from adult tissue, plants were grown in soil (Metro-Mix 360; Scotts, Maryville, OH, USA) in a walk-in growth chamber at $24^{\circ} \mathrm{C}, 70 \% \mathrm{RH}$ and $\sim 130 \mu \mathrm{E} \mathrm{m}^{-2} \mathrm{~s}^{-1}$ under cool white fluorescent lights with a $16 \mathrm{~h}$ photoperiod.

The gh3.9-1 mutant (female) was backcrossed to the wild-type Col-0 parent (male), and two F1 progeny were allowed to self fertilize. The resulting two independent F2 populations were analyzed for the segregation of primary root length phenotype, and the data was subjected to chi-square goodness of fit analyses. PCRbased genotyping (described below) was used to verify the recessive nature of the gh3.9-1 associated long-root phenotype.

Exogenous IAA treatment of seedlings was performed as described (Takase et al. 2004). Briefly, 4-6 leaf stage Col-0 or GH3.9 promoter:: $\beta$-glucuronidase (GUS) transgenic seedlings were treated by immersing in aqueous solutions with $0,0.01,0.1$ or $100 \mu \mathrm{M}$ IAA for $60 \mathrm{~min}$. RNA was isolated immediately after treatment using Qiagen mini RNeasy kit (Qiagen, Valencia, CA, USA) according to manufacturer's instructions followed by reverse transcription and polymerase chain reaction (RT-PCR) (described below).

\section{Retrieval of plant DNA flanking the T-DNA insertion by inverse PCR}

The plant DNA flanking the T-DNA insertion in gh3.9-1 was identified by inverse PCR (iPCR) using oligonucleotide primers corresponding to regions of the pSKI015 T-DNA insertion region as described with modifications (Zhou et al. 1997). Specifically, genomic DNA $(7 \mu \mathrm{g})$, isolated from leaf tissue using Nucleon Phytopure Plant DNA Extraction Kit (Amersham Biosciences, Picataway, NJ, USA), was restriction enzyme digested in a $100 \mu \mathrm{l}$ reaction with $10 \mathrm{U}$ EcoRI enzyme (Promega, Madison, WI, USA) overnight at $37^{\circ} \mathrm{C}$, extracted with phenol/chloroform/isoamyl alcohol (25:24:1), and precipitated with ethanol. Digested DNA (560 ng) was self-ligated in a $100 \mu \mathrm{l}$ reaction at $16^{\circ} \mathrm{C}$ using $10 \mathrm{U}$ of T4 DNA ligase and used as a template for the PCR reaction. PCR was performed for $40 \mathrm{cy}$ cles $\left(94^{\circ} \mathrm{C} 1 \mathrm{~min}, 50.5^{\circ} \mathrm{C} 1 \mathrm{~min}\right.$, and $\left.72^{\circ} \mathrm{C} 4 \mathrm{~min}\right)$ in a reaction containing $200 \mu \mathrm{M}$ dNTPs, 1X TaqPlus Precision buffer, 1.25 U TaqPlus Precision polymerase mix 
(Stratagene, La Jolla, CA, USA) and $100 \mathrm{nM}$ oligonucleotide primers. Oligonucleotide primers were ACTRB5': 5'-GTTTCTAGATCCGAAACTATCAGTG-3' and T3: 5'-AATTAACCCTCACTAAAGGGAACAAAAG-3'. The resulting PCR product was purified using a PCR purification kit (Qiagen, Valencia, CA, USA), subcloned into pGEMTeasy vector (Promega, Madison, WI, USA) and subjected to DNA sequencing with T7 promoter and SP6 promoter oligonucleotide primers (UNL Genomics Core Facility).

\section{PCR-based genotyping}

The genotypes of the parents and F2 progeny from a backcross between a gh3.9-1 homozygous T-DNA insertion mutant and wild-type Col-0 were verified by PCRbased genotyping. Genomic DNA was isolated from $100 \mathrm{mg}$ leaf tissue using the Dellaporta method (Dellaporta et al. 1983) and subjected to PCR using GH3.9-specific oligonucleotide primers flanking the T-DNA insertion (p50 F: 5'-CCTTGATTTGACTTGGTGTAG-3' and p50 R: 5'-ggatccTCTTTTAATACACTGTCGTG-3') to detect a wild-type allele and p50 F and a T-DNA specific oligonucleotide primer TR2: 5'-TACGACGGATCGTAATTTGTCG-3' to detect a T-DNA insertion allele. The lowercase letters in the p50 R oligonucleotide primer represents an engineered Bam $\mathrm{HI}$ restriction enzyme site, and the TR2 primer corresponds to the left border region of the activation tagging T-DNA vector pSKI015. PCR was performed for 40 cycles in a $25 \mu 1$ reaction containing 1X high fidelity PCR buffer, 1.25 U Eppendorf Triple Master mix enzyme (VWR International, West Chester, PA, USA), $50 \mu \mathrm{M}$ dNTPs, and $500 \mathrm{nM}$ oligonucleotide primers. A wild-type allele yielded a GH3.9specific $2.6 \mathrm{kbp}$ PCR product with p50 F and p50 R oligonucleotide primers and $94^{\circ} \mathrm{C} 30 \mathrm{~s}, 55^{\circ} \mathrm{C} 30 \mathrm{~s}$, and $72^{\circ} \mathrm{C}$ 2.5 min cycling conditions. A T-DNA insertion allele yielded a $1.5 \mathrm{kbp}$ PCR product with p50 F and TR2 oligonucleotides and $94^{\circ} \mathrm{C} 30 \mathrm{~s}, 55^{\circ} \mathrm{C} 30 \mathrm{~s}$, and $72^{\circ} \mathrm{C} 1.5 \mathrm{~min}$ cycling conditions. PCR products were visualized after electrophoresis on $1 \%$ agarose gels.

\section{Generation of GH3.9 RNA-interference (RNAi) and GH3.9 promoter:: GUS gene fusion transgenic lines}

An RNA-interference (RNAi) approach was used to generate transgenic lines with reduced expression of GH3.9. A GH3.9-specific region was cloned in two orientations in the binary vector pFGC5941 designed to produce double-stranded RNA in a hairpin structure for efficient gene silencing (Wesley et al. 2001). Total RNA was isolated from mature Col-0 plants using
Trizol reagent (Invitrogen, Carlsbad, CA, USA) according to manufacturer's instructions, and RNA concentration was determined spectrophotometrically. Reverse transcription was performed for $1 \mathrm{~h}$ at $42^{\circ} \mathrm{C}$ in a $20 \mu \mathrm{l}$ reaction containing $2 \mu \mathrm{g}$ total RNA, $500 \mathrm{ng}$ random hexamer oligonucleotide primers, $40 \mathrm{U}$ RNasin (Promega, Madison, WI, USA), $500 \mu \mathrm{M}$ dNTPs, and $40 \mathrm{U}$ M-MuLV reverse transcriptase (Fermentas, Hanover, MD, USA), then diluted to $50 \mu \mathrm{l}$. Polymerase chain reaction (PCR) was performed for 40 cycles $\left(94^{\circ} \mathrm{C}\right.$ $30 \mathrm{~s}, 58^{\circ} \mathrm{C} 30 \mathrm{~s}$, and $72^{\circ} \mathrm{C} 40 \mathrm{~s}$ ) in a $50 \mu 1$ reaction containing 1X PCR buffer, $1 \mathrm{mM} \mathrm{MgCl}, 50 \mu \mathrm{M}$ dNTPs, $500 \mathrm{nM}$ each of $\mathrm{Ri} 50 \mathrm{~F}$ and $\mathrm{Ri} 50 \mathrm{R}$ oligonucleotide primers, and Taq polymerase. The forward primer Ri 50F: 5'-tctagaggcgcgccGGAGCATAACGTTAGCCAAG-3' and reverse primer Ri 50R: 5'-ggatccatttaaatTCATGGAACCCAAGTCGGG-3' amplify a $410 \mathrm{bp}$ gene-specific region of GH3.9 (Figure 1). Lowercase letters represent the engineered restriction enzyme sites, $\mathrm{Xba \textrm {I }}$ and $\mathrm{AscI}$ in Ri 50F and BamHI and SwaI in Ri 50R. The PCR product was ligated into the pGEMTeasy vector (Promega, Madison, WI, USA) and verified by DNA sequencing with T7 promoter and SP6 promoter oligonucleotide primers (UNL Genomics Core Facility). The GH3.9-specific region was first isolated by restriction enzyme digestion with $A s c \mathrm{I}$ and SwaI, purified on an agarose gel, and ligated into the AscI/SwaI digested RNAi vector pFGC5941. Next, the GH3.9-specific region was first isolated by restriction enzyme digestion with $\mathrm{Xba \textrm {I }}$ and BamHI, purified on an agarose gel, and ligated into the XbaI/BamHI digested pFGC5941 vector containing the AscI/SwaI fragment. The resulting pFGC5941-RNAiGH3.9 construct was used to generate transgenic plants (see below).

To examine the tissue-specific and developmental expression of GH3.9, transgenic plants expressing a GH3.9 promoter:: $\beta$-glucuronidase (GUS) fusion construct were generated. The wild-type GH3.9 promoter region containing $1192 \mathrm{bp}$ upstream of and $33 \mathrm{bp}$ downstream of the ATG translation start codon was amplified by PCR from Col-0 genomic DNA. The PCR reaction was performed for 40 cycles $\left(94^{\circ} \mathrm{C} 30 \mathrm{~s}\right.$, $55^{\circ} \mathrm{C} 30 \mathrm{~s}, 72^{\circ} \mathrm{C} 1.5 \mathrm{~min}$ ) in a $50 \mu \mathrm{l}$ reaction containing 1X high fidelity PCR buffer, 1.25 U Eppendorf Triple Master mix enzyme(VWR International, West Chester, PA, USA), $100 \mu \mathrm{M}$ dNTPs, and $500 \mathrm{nM}$ oligonucleotide primers new p50 F: 5'-ggatccGAGTGTGAATTCCATTAACACGG-3' and new p50 R: 5'-ggatccCCTACACTGTCGTGATCAAGCTTC-3'. Lowercase letters represent the engineered $\mathrm{BamHI}$ restriction enzyme site and bold letters in the new p50 R oligonucleotide primer represent extra bases added to create an in-frame fu- 


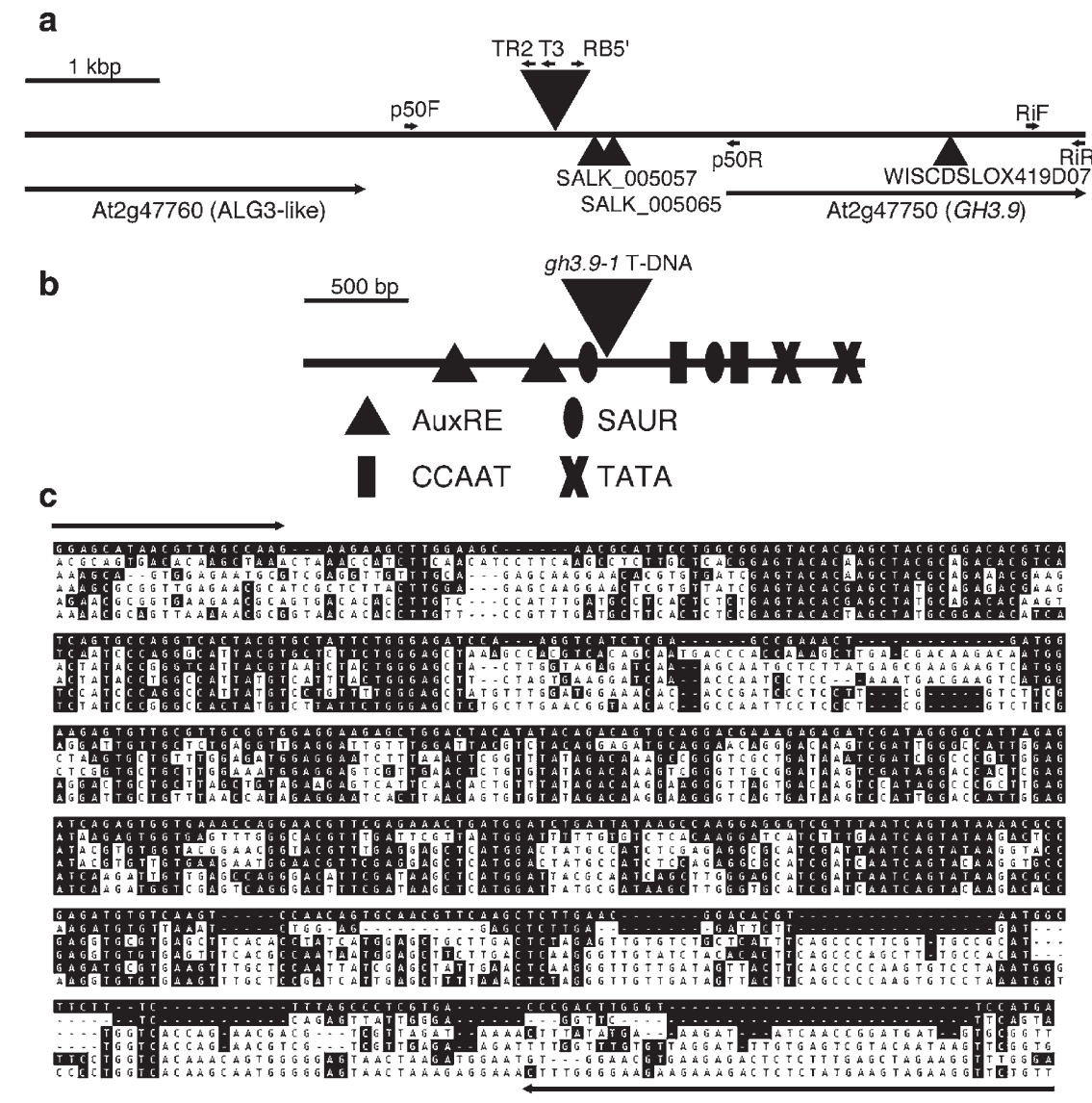

Figure 1. Schematic representation of the T-DNA insertions in the gh3.9 mutants, the relative positions of various promoter elements in the GH3.9 upstream region, and a nucleotide alignment of several Group II GH3 cDNAs highlighting the region used for gene silencing by RNA-interference, semi-quantitative RT-PCR and a hybridization probe. a) The original gh3.9-1 mutant was found to have an activation tagging T-DNA insertion (derived from pSKI015-large triangle) inserted in Chromosome 2 in the intergenic region between At2g47750 and At2g47760 (coding regions from the translation start to translation stop sequences are represented by arrows). Positions of additional T-DNA insertions corresponding to SALK_005057, SALK_005065 and WISCDSLOX419D07 lines are indicated by small triangles. Oligonucleotide primer annealing sites are indicated with small arrows. Oligonucleotide primers corresponding to the T3 promoter (T3) and the right border region of pSKI015 (ACTRB5'; RB5') were used for retrieval of the plant DNA flanking the activation tagging T-DNA by inverse PCR. For PCR-based genotyping p50 F, p50 R (genespecific primers) and TR2 (a T-DNA-specific primer) were used. Oligonucleotide primers Ri 50F (RiF) and Ri 50R (RiR) were used for semi-quantitative RT-PCR and to generate the GH3.9 RNAi gene silencing construct and hybridization probe for Northern blot analyzes. b) Schematic representation of the intergenic region from the stop codon of At2g47760 to the start codon of GH3.9 and selected cis regulatory elements. The locations of the basal promoter elements (TATA and CCAAT boxes) and auxin-responsive cis elements (AuxRE:TGTCTC and SAUR:CATATG) are shown relative to the T-DNA insertion in the original gh3.9 mutant (large triangle). $\mathrm{c}$ Regions at the 3' end of the coding sequences of cDNAs corresponding to the closely related Group II GH3 family members (GH3.9, GH3.17, GH3.2/YDK1, GH3.3, GH3.5/AtGH3a, and GH3.6/DFL1, top to bottom) were aligned by the Clustal method using DNAStar software (Madison, WI). Nucleotides that match the sequence of GH3.9 are shaded in black. Annealing sites for oligonucleotide primers (Ri 50F and Ri 50R) for gene-specific, semi-quantitative RT-PCR and to generate the RNAi construct and Northern blot hybridization probe are indicated by arrows.

sion to the GUS gene in pCAMBIA3301. The PCR product was ligated into the pGEMTeasy vector (Promega, Madison, WI, USA) and sequenced. Next, the cloned fragment in pGEMTeasy was isolated by restriction enzyme digestion with $B a m \mathrm{HI}$ and ligated into the BamHI-digested pCAMBIA3301 vector. Correct orientation was verified by restriction enzyme mapping and DNA sequencing. The resulting pCAMBIA3301-GH3.9 promoter construct was used to generate transgenic plants (see below).

The pFGC5941-RNAiGH3.9 and pCAMBIA3301GH3.9 promoter constructs were electroporated into Agrobacterium tumefaciens strain GV3101. Transgenic plants were generated in the Col-0 ecotype by the floral dip method (Clough and Bent 1998). The pFGC5941 and pCAMBIA3301 vectors carry genes that confer re- 
sistance to the herbicide Basta ${ }^{\mathrm{TM}}$. Therefore, primary transformants were selected by spraying plants with 1:100 dilution of the herbicide Finale ${ }^{\mathrm{TM}}$ (AgrEvo Environmental Health, Montvale, NJ, USA). Plants homozygous for the T-DNA insertion were identified in subsequent generations.

The GH3.9 RNAi lines were used for Northern (RNA) blot analysis and hormone sensitivity root growth assays. The GH3.9 'promoter'::GUS lines were used for determining tissue and developmental expression patterns by histochemical staining using 5-bromo-4-chloro-3indolyl- $\beta$-glucuronic acid (X-Gluc) as a substrate (Jefferson 1987).

\section{Semi-quantitative RT-PCR and Northern (RNA) blot analyses}

For semi-quantitative RT-PCR to determine whether GH3.9 is auxin-responsive, total RNA was isolated from 4 to 6 leaf stage Col-0 seedlings treated with IAA as described above using the Qiagen mini RNAeasy kit (Qiagen, Valencia, CA, USA) according to manufactur$\mathrm{er}^{\prime}$ 's instructions, and RNA concentration was determined spectrophotometrically. Reverse transcription was performed as described above except that $2.4 \mu \mathrm{g}$ total RNA was used in each reaction. PCR was performed for 30 cycles $\left(94^{\circ} \mathrm{C} 30 \mathrm{~s}, 58^{\circ} \mathrm{C} 30 \mathrm{~s}, 72^{\circ} \mathrm{C} 40 \mathrm{~s}\right.$ ) in a $25 \mu 1$ reaction containing 1X Econo Taq PCR buffer, 1.25 U Eppendorf Triple Master mix enzyme(VWR International, West Chester, PA, USA), $50 \mu \mathrm{M}$ dNTPs, and $500 \mathrm{nM}$ Ri 50F and Ri 50R oligonucleotide primers. As loading controls, the reverse-transcribed RNA was also subjected to PCR using an 185 primer pair (Ambion, Austin, TX, USA) and primers to $A C$ TIN2 (At3g18780) ACT2 F: 5'-GTGCCAATCTACGAGGGTTTC-3' and ACT2 R: 5'- CAATGGGACTAAAACGAAAA-3' for 25 cycles. The RT-PCR reactions (15 $\mu \mathrm{l}$ ) were electrophoretically resolved by agarose gel electrophoresis.

The total RNA blot representing transcripts from different $A$. thaliana plant organs was kindly provided by Steve Pechous (National Center for Biotechnology Information, Bethesda, MD, USA). To determine GH3.9 expression in different genotypes and RNAi transgenic lines, total RNA was isolated from tissue comprising both mature and immature siliques and some flowers using an SDS-phenol extraction procedure followed by $\mathrm{LiCl}$ precipitation essentially as described (Downing et al. 1992). Total RNA (15 $\mu \mathrm{g})$ was electrophoresed on a $1.2 \%$ formaldehyde-agarose gel and blotted overnight in 20X SSC (3 M sodium chloride, $0.3 \mathrm{M}$ sodium citrate, $\mathrm{pH}$ 7.0) to a Hybond-N mem- brane (Amersham Biosciences, Piscataway, NJ, USA). Radio-labeled hybridization probe was generated by performing PCR for 20 cycles $\left(95^{\circ} \mathrm{C} 30 \mathrm{~s}, 50^{\circ} \mathrm{C} 45 \mathrm{~s}\right.$, and $72^{\circ} \mathrm{C} 1 \mathrm{~min}$ ) in a reaction containing $500 \mathrm{nM}$ dNTPs (minus dCTP), $2.5 \mathrm{mM} \mathrm{MgCl}_{2}, 500 \mathrm{nM}$ Ri 50R oligonucleotide primer, and $\mathrm{a}^{3}\left[{ }^{32} \mathrm{P}\right] \mathrm{dCTP}$. The RNA blot was hybridized in formamide buffer (5X SSPE, 50\% formamide, 5X Denhardt's and 1\% SDS solution) at $42{ }^{\circ} \mathrm{C}$ overnight then washed under high stringency conditions in 2X SSC and 1\% SDS solution two times for $5 \mathrm{~min}$ each at room temperature followed by $85 \mathrm{~min}$ at $65^{\circ} \mathrm{C}$ (Ausubel et al. 2006) and exposed to a phosphoimager screen (Biorad, Hercules, CA, USA). The blot was stripped in 0.1 X SSC and $0.1 \%$ SDS and hybridized with a radiolabeled UBQ5 probe. A 250 bp fragment of UBQ5 was amplified by PCR using UBQ5 F: 5'-GTGGTGCTAAGAAGAGGAAGA-3' and UBQ5 R: 5'-TCAAGCTTCAACTCCTTCTTT-3' oligonucleotide primers and cloned into pGEMTeasy vector (Promega, Madison, WI, USA). This cloned fragment was used as a template to generate radiolabeled probe by PCR as described for the GH3.9 hybridization probe using the UBQ5 R oligonucleotide primer.

\section{Results}

The GH3 Group II member, GH3.9, does not appear to be induced by exogenous auxin and is developmentally regulated

Inverse PCR was used to identify and activation tagged T-DNA in chromosome 2 in the promoter region of GH3.9 between the 3'UTR of At2g47760 (ALG3-like gene) and the 5'UTR of At2g47750, GH3.9 (Figure 1a). GH3.9 belongs to the Group II class of the GH3 gene family of proteins that are proposed to act as IAA amido synthetases to conjugate auxin to amino acids (Staswick et al. 2002, 2005). As several Group II members have been shown to be "auxin-responsive", the promoter region was searched for hormone-responsive cis regulatory elements using the PLACE database (Higo et al. 1999). Figure $1 \mathrm{~b}$ shows the positions of auxin-response elements (AuxRE), small-auxin upregulated elements (SAUR), CCAAT box motifs and TATA box motifs relative to the T-DNA insertion in gh3.9-1. As the A. thaliana GH3 family members share high sequence similarity, a multiple alignment of the Group II member cDNAs was performed to identify the most divergent region to perform GH3.9-specific semi-quantitative RT-PCR and generate a GH3.9-specific hybridization probe for Northern blot analysis and an RNAi construct (Figure 1c). 


\section{a}
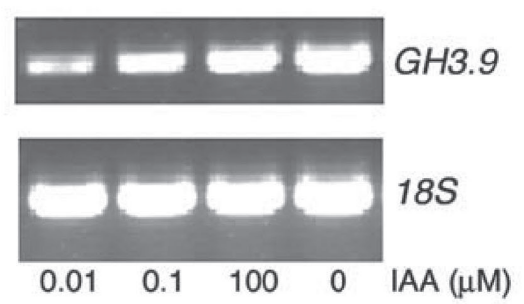

C

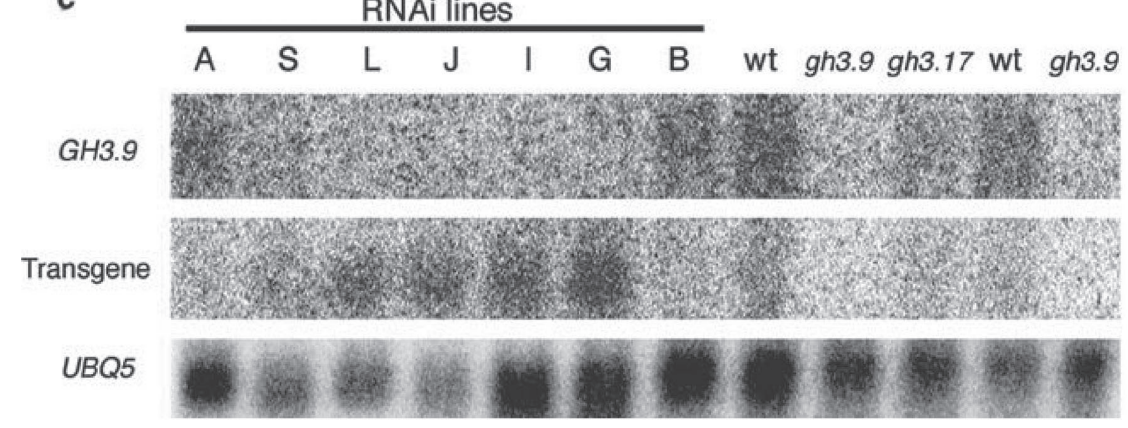

b

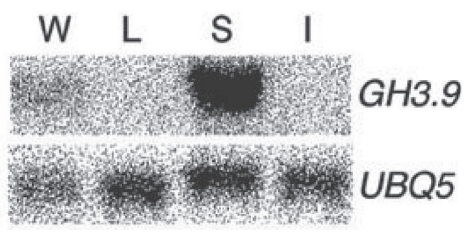

Figure 2. Steady-state GH3.9 transcript levels are not increased by exogenous auxin in seedlings, are expressed in a tissue-specific manner and are reduced in the gh3.9 mutant and RNAi gene silencing transgenic lines. a) Semi-quantitative RT-PCR was used to determine whether exogenous indole-3-acetic acid (IAA) increased GH3.9 expression. Seedlings were mock treated (0) or incubated with increasing concentrations of IAA $(0.01,0.1$, and $100 \mu \mathrm{M})$. Similar results were obtained in three independent experiments, using $18 S$ or ACTIN2 as RNA loading controls. GH3.9 expression is suppressed at low concentrations of exogenous IAA. b) Northern (RNA) blot analysis of GH3.9 (At2g47750) gene in wild-type Col-0 plants. Total RNA was isolated from whole plant $(W)$, leaves $(L)$, siliques $(S)$, and inflorescences $(I)$. The same 410 bp exon region of GH3.9 used to generate the RNAi construct was used as a hybridization probe. Expression of the UBQ5 gene was used as a loading control. GH3.9 transcript accumulates more in siliques compared to whole plant and is undetectable in leaves or inflorescences. c Northern (RNA) blot analysis of GH3.9 (At2g47750) in wild-type (wt) Col-0, gh3.9, gh3.17, and transgenic RNAi lines A, S, L, J, I, G, and B. Total RNA was isolated from $1 \mathrm{~g}$ silique when siliques were largely mature. Fifteen micrograms (15 $\mathrm{gg})$ of total RNA was loaded in each lane. GH3.9 transcript is not detectable or reduced in the gh3.9 mutant and moderately expressed in the gh3.17 mutant compared to wild-type Col-0. T3 transgenic RNAi lines have variable levels of suppression of GH3.9, which is inversely correlated with the expression of the transgene. GH3.9 transcript level in gh3.17 is very similar to Col-0. Detection of UBQ5 transcript was used as a control.

We examined the expression of GH3.9 in A. thaliana tissues by semi-quantitative RT-PCR and Northern blot analyses. GH3.9 expression was undetectable by Northern blot analysis of mature leaf tissue (Figure $2 b$ and data not shown). However, RT-PCR was sufficiently sensitive to detect GH3.9 in seedlings. The RT-PCR should detect only GH3.9 and not other Group II-family members based on the specificity of the oligonucleotide primers used (Figure 1c). To determine whether GH3.9 is indeed an auxin-responsive gene, seedlings were treated with various concentrations of exogenous IAA. Auxin treatment failed to enhance GH3.9 expression and actually somewhat repressed expression ( $70 \%$ of untreated as determined by semiquantitative RT-PCR) at low IAA concentrations (Figures $2 \mathrm{a}, 3 \mathrm{e}, \mathrm{f})$. Our data is consistent with publicly available microarray expression data suggesting that GH3.9 is repressed by exogenous IAA application at low concentrations and unaffected at high concentrations (Zimmermann et al. 2004).
To learn whether GH3.9 is expressed in a developmental or tissue-specific manner, Northern RNA blot analysis was performed on total RNA isolated from different tissues of wild-type Col-0 including leaves, flowers, siliques, and whole plants. We observed greater expression of GH3.9 in siliques compared to the whole plant, whereas no detectable expression was observed in leaves or flowers (Figure 2b). These results are consistent with publicly available microarray data (Zimmermann et al. 2004; Toufighi et al. 2005).

The steady-state level of GH3.9 transcripts is reduced in the gh3.9-1 mutant and lines where GH3.9 was targeted for silencing by RNAi. GH3.9 expression is reduced to $\sim 50 \%$ of the level in wild type in the gh3.9-1 mutant. We observed a range of suppression in the RNAi lines ( $60-90 \%$ of wild-type levels). In addition, we performed semi-quantitative RT-PCR several times with similar results (data not shown). Although the signal for GH3.9 is very low (particularly as compared to that for UBQ5), we chose to show a Northern blot, be- 
a
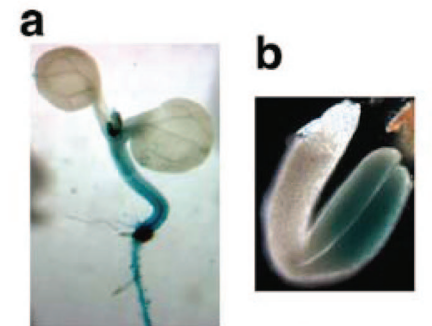

C

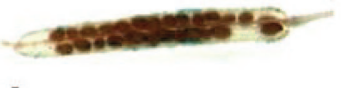

d
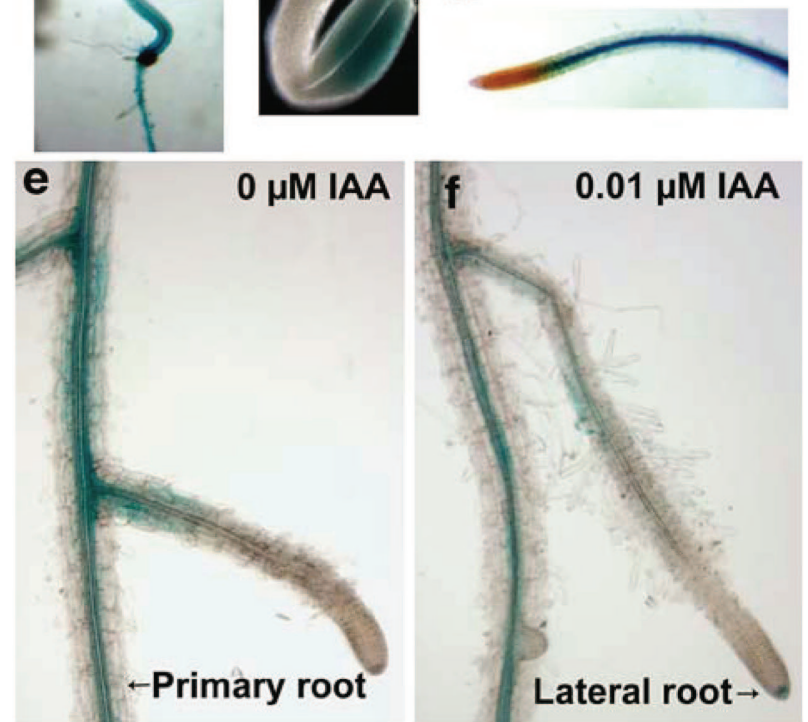

Figure 3. GH3.9 promoter::GUS transgenic plants indicate that GH3.9 is expressed in tissue-specific and developmentally regulated manners. Representative examples of histochemical detection of GUS activity in (a) a young seedling, (b) a mature embryo, (c) a mature silique, (d) a primary root, (e and f) primary and lateral roots untreated or treated with $0.01 \mu \mathrm{M}$ IAA, respectively.

cause the correlation between transgene expression and GH3.9 suppression is evident. RNAi lines $G, J, L$, and $S$ showed significantly reduced GH3.9 expression compared to RNAi lines $A$ and $B$ that was inversely correlated with transgene expression levels (Figure 2c). The level of suppression generally correlated with the strength of the long-root phenotype. For example, we saw the least suppression in GH3.9 RNAi line B, and this line had the shortest roots (closer to wild type) in all experiments (Figures 4, 6a). Because GH3.17 is the closest gene family member to GH3.9, we also analyzed the expression of GH3.9 in the mutant gh3.17-1. In the mutant gh3.17-1, GH3.9 transcript accumulated to similar levels to wild-type Col-0 (Figure 2c).

Further support for tissue specificity and developmental control of GH3.9 expression comes from histochemical staining of GH3.9 promoter::GUS transgenic plants. Strong GUS expression at the root-hypocotyl junction, young leaves and the shoot apical meristem, but only weak expression in cotyledons of young seedlings were observed (Figure 3a). The strong silique GH3.9 expression seen by Northern blot (Figure 2b) can primarily be attributed to weak, but detectable, GUS expression in the outer wall of the fruit bodies or siliques and significant expression in mature embryos prior to
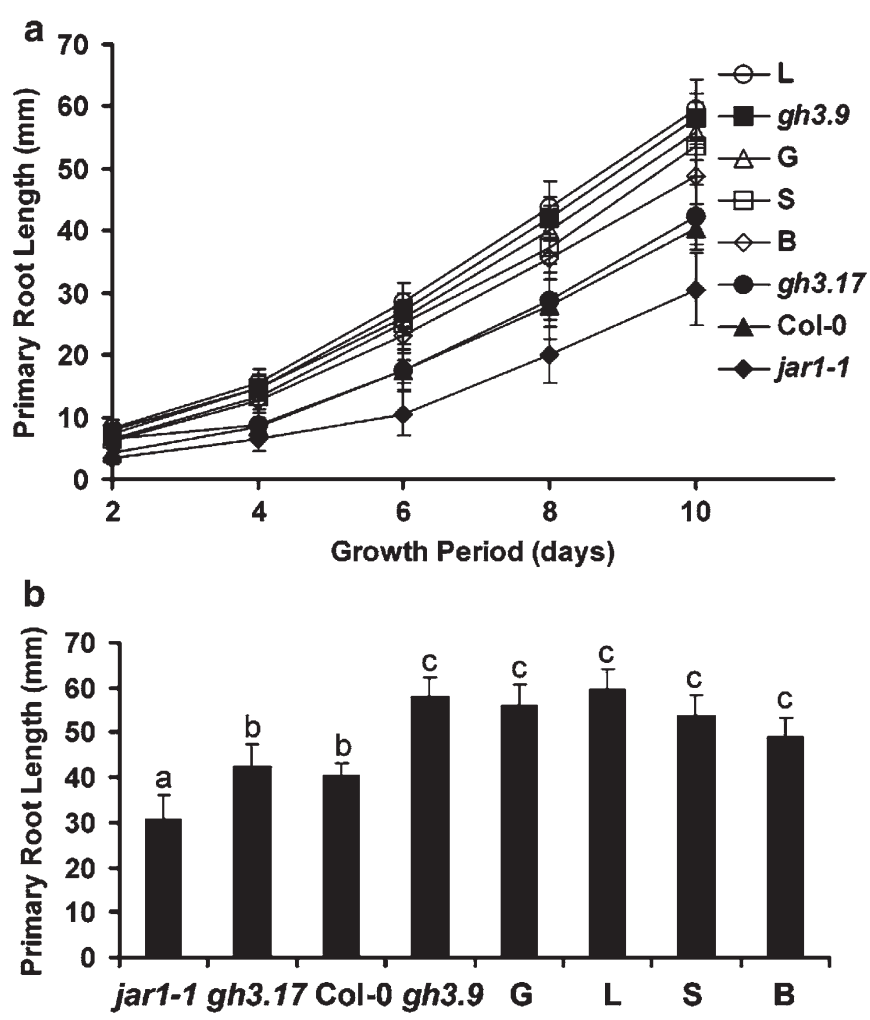

Figure 4. The gh3.9-1 mutant and GH3.9 RNAi lines display long primary roots compared to wild-type Col-0 and the gh3.17-1 and jar1-1 mutants when grown vertically on $\mathrm{Mu}-$ rashige-Skoog $(M S)$ media. a) A line graph depicting primary root lengths determined over a period of 10 days after seed germination. Homozygous T3 generations of transgenic RNAi lines were analyzed, and data is combined from three independent experiments. Error bars represent 95\% confidence levels. b) A bar graph depicts the primary root lengths for the analyzed genotypes at the end of the experiment (day 10). Error bars represent $95 \%$ confidence levels. Significant differences between genotypes, determined by two-sample equal variance one-tailed Student's $t$-tests, are indicated by different alphanumeric symbols $(a=0.05)$. Different letters represent significant differences.

germination (Figure 3b, c). In roots, the promoter was active in the vascular tissue of the root elongation zone (Figure 3d). Exogenous IAA treatment caused reduced promoter activity in the vascular tissue (consistent with the RT-PCR results, Figures 2a, 3e, f). Interestingly, IAA treatment triggered lateral root tip expression (Figure 3e, f), with only $13 \%$ of untreated lateral roots $(n=131)$ and $57 \%$ of treated lateral roots $(n=76)$ showing any expression at the tip. We failed to detect any changes in either the levels or the distribution of GUS activity in response to exogenous $10 \mu \mathrm{M}$ MeJA treatment (data not shown). Therefore GH3.9 expression is developmentally regulated. Moreover, GH3.9 appears to respond to exogenous auxin, but by repression rather than induction, and a change in the tissue localization in lateral roots. 
GH3.9 affects primary root growth and GH3.9 gene expression correlates with a long primary root phenotype

We observed consistently longer primary roots in gh3.9-1 seedlings compared to wild-type Col-0 seedlings (Figure 4). Because the T-DNA insertion in gh3.9-1 is derived from the activation tagging vector pSKI015, we expected that the long-root phenotype might be dominant gain-of-function (Weigel et al. 2000). Therefore, the gh3.9-1 mutant was backcrossed to wild-type Col-0, and the primary root lengths were analyzed for two independent $\mathrm{F} 2$ populations. The wild-type (short) and mutant (long) root phenotypes were distinguished by the value of the longest Col- 0 root. The long-root phenotype segregated in a 3:1 (short root: long root) ratio $\left(\chi^{2}=0.10, n=118\right)$, as would be expected if the long-root phenotype were conferred by a single recessive mutation, rather than by a gain-of-function mutation. Furthermore, the gh3.9-1 mutant showed a reduction in the GH3.9 transcript, rather than an increase in RNA levels (Figure 2c), thereby confirming the notion that the T-DNA causes a loss-of-function mutation. PCR-based genotyping was consistent with this finding (data not shown). As further verification that the long-root phenotype was due to GH3.9 disruption, additional homozygous T-DNA insertion alleles were tested. SALK_005057 and SALK_005065 have pROK2derived T-DNA sequences (Alonso et al. 2003) inserted 302 and $415 \mathrm{bp}$, respectively, removed from the site of the pSKI015-derived T-DNA insertion in gh3.9-1 and WiscDsLox419D07 has pDS-LOX-derived T-DNA sequences (Medberry et al. 1995) in exon 3 of the coding region of GH3.9 (Figure 1a). Homozygous insertion mutants for two of these alleles also exhibited the long-root phenotype (Table 1), and the heterozygous WiscDsLox line segregated for the long-root phenotype (data not shown). Moreover, GH3.9 RNAi lines also had longer primary roots compared to wild-type Col-0 seedlings. Mutation of the Group II GH3 gene family member most closely related to GH3.9, GH3.17, had no significant effect on primary root length, while mutation of a Group I GH3 gene family member, GH3.11 or JAR1, resulted in shorter primary roots than Col-0, gh3.9-1, gh3.17-1, and GH3.9 RNAi lines (Figure 4). These results indicate that GH3.9 influences primary root length, and that the long-root phenotype correlated with reduced GH3.9 expression in gh3.9-1 and GH3.9 RNAi lines. Rates of root elongation in the gh3.9-1 mutant and GH3.9 RNAi lines were similar to wild-type seedlings in the early stages of root growth and became accelerated with time (Figure 4a, Table 2). No significant difference in lateral root numbers were observed for the gh3.9-1 mutant and wild type.
Table 1. Primary root length determined for GH3.9-related TDNA insertion lines

\begin{tabular}{lll}
\hline Genotypes & No. seedlings $^{\mathrm{a}}$ & Root length $(\mathrm{mm})^{\mathrm{b}}$ \\
\hline Col-0 & 16 & $50.9(7.9)^{1,3}$ \\
gh3.9-1 & 18 & $59.4(8.5)^{2}$ \\
SALK_005065 & 17 & $65.4(9.0)^{2}$ \\
SALK_005057 & 16 & $59.0(9.6)^{2,3}$ \\
\hline
\end{tabular}

${ }^{a}$ The number of seedlings tested per genotype

$\mathrm{b}$ The mean primary root length determined 10 days after seed germination and error at 95\% confidence intervals (in parentheses) are shown. Significant differences between genotypes, determined by paired, one-tailed Student's $t$-tests are indicated by different superscripted numbers $(\alpha=0.1)$

Table 2. Primary root growth rates for various genotypes

\begin{tabular}{llll}
\hline Genotype & \multicolumn{3}{c}{ Root growth rate $\left(\mathrm{mm} \mathrm{day}^{-1}\right)^{\mathrm{a}}$} \\
& Days 4-6 & Days 6-8 & Days 8-10 \\
\hline Col-0 & 4.45 & 5.22 & 6.27 \\
gh3.9-1 & 6.14 & 7.49 & 8.00 \\
RNAi-L & 6.46 & 7.64 & 7.86 \\
RNAi-G & 5.58 & 7.09 & 7.95 \\
RNAi-S & 5.93 & 6.17 & 8.10 \\
RNAi-B & 5.15 & 6.19 & 6.67 \\
gh3.17-1 & 4.38 & 5.57 & 6.78 \\
jar1-1 & 2.04 & 4.72 & 5.30 \\
\hline
\end{tabular}

a Primary root lengths were determined over a 10-day period after seed germination. The average root growth rate $\left(\mathrm{mm} \mathrm{day}{ }^{-1}\right)$ is shown for various time intervals

\section{GH3.9 has moderate influence on sensitivity to jasmonate-mediated and auxin-mediated root growth inhibition}

Several A. thaliana GH3 family member mutants have observable phenotypes, including altered sensitivity to plant hormones such as IAA and MeJA (Staswick et al. 1992, 2005; Tiryaki and Staswick 2002; Staswick and Tiryaki 2004). Therefore gh3.9-1 and the GH3.9 RNAi lines were tested for sensitivity to MeJA- and IAA-mediated root growth inhibition. The concentrations used in the experiments shown were based on these standardization experiments, information for GH3.9 expression available from the Genevestigator microarray expression database, and published literature characterizing the other gene family members. The data is shown for concentrations that gave reproducible results and are consistent with those used by other researchers (Staswick et al. 1992, 2005; Tiryaki and Staswick 2002; Staswick and Tiryaki 2004). The MeJA-insensitive jar1-1 mutant and 

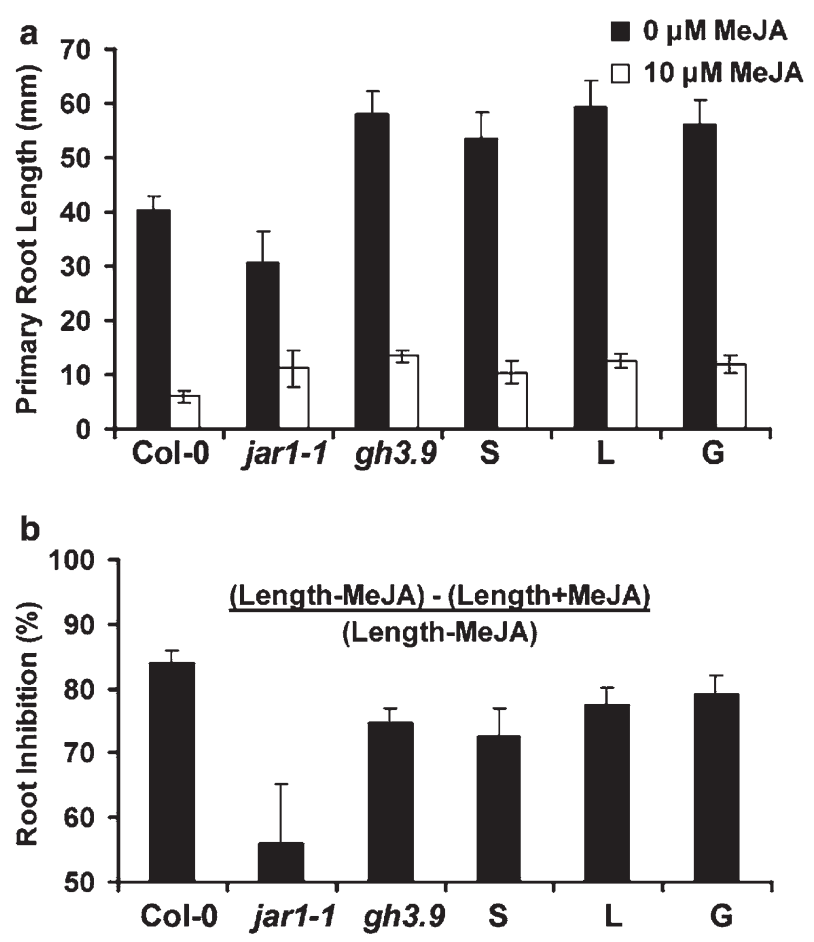

Figure 5. The gh3.9-1 mutant and the GH3.9 RNAi transgenic lines are moderately resistant to root growth inhibition by methyl jasmonate (MeJA). a) The mean root length at 10 days after seed germination is indicated for seedlings grown in the absence of exogenous MeJA (black bars) and the presence of $10 \mu \mathrm{M}$ MeJA (white bars). Error bars represent 95\% confidence levels. The jar1-1 mutant was used as a control for MeJA resistance. b) The MeJA-induced root inhibition (\%) was calculated as the difference in root length in the presence and absence of MeJA divided by the root length in the absence of MeJA; [(length - MeJA) - (length + MeJA)]/(length - MeJA). Data represent 14-20 individual seedlings of each genotype.

the auxin-sensitive gh3.17-1 were used as controls. In the presence of $10 \mu \mathrm{M}$ MeJA and $5 \mu \mathrm{M}$ IAA, primary root growth of wild-type Col-0 seedlings was dramatically inhibited (Figures 5a, 6a). Root growth inhibition (percent) was calculated to compensate for the fact that gh3.9-1 and the GH3.9 RNAi lines had long primary roots on unsupplemented media (Figures 4, 5a, 6a).

The gh3.9-1 mutant and the GH3.9 RNAi lines were moderately resistant to MeJA, as they differ from the highly sensitive Col-0 and the resistant jar1-1 mutant (Figure 5b). The gh3.9-1 mutant and the GH3.9 RNAi lines were moderately sensitive to IAA, as they displayed greater sensitivity than wild-type Col-0, but less sensitivity than gh3.17-1 (Figure 6b).

\section{Discussion}

Auxin synthesis, degradation, conjugation, and transport control free auxin levels and distribution
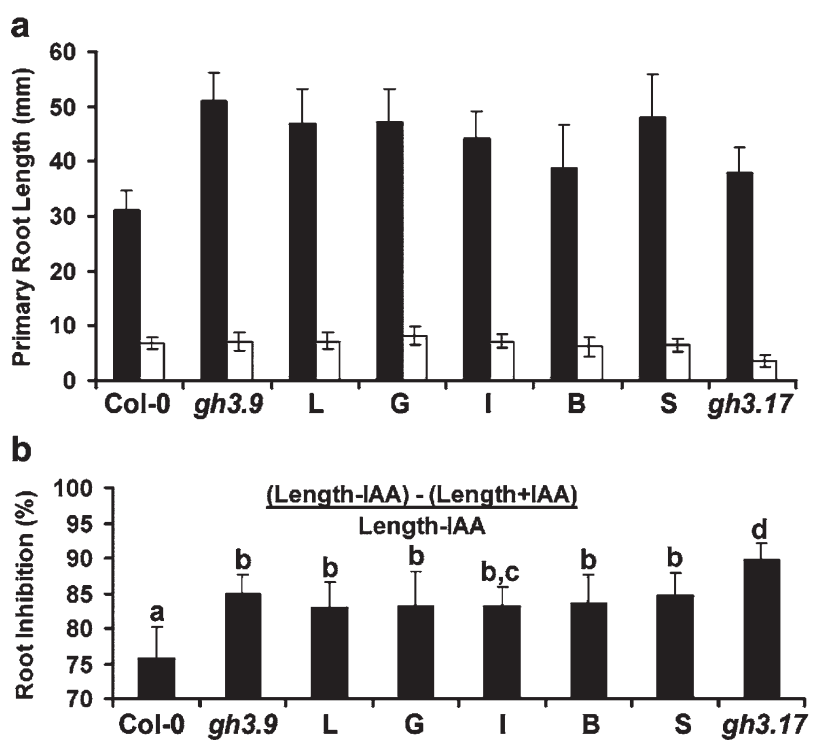

Figure 6. The gh3.9-1 mutant and the GH3.9 RNAi transgenic lines are moderately sensitive to root growth inhibition by IAA. a) The mean root length at 10 days after seed germination is indicated for seedlings grown in the absence of exogenous IAA (black bars) and the presence of $5 \mu \mathrm{M}$ IAA (white bars). Error bars represent 95\% confidence levels. The gh3.17-1 mutant was used as a control for IAA sensitivity. b) The IAAinduced root growth inhibition (\%) was calculated as the difference in root length in the presence and absence of IAA divided by the root length in the absence of IAA; [(length IAA) - (length + IAA)]/(length - IAA). Error bars represent 95\% confidence levels. Significant differences between genotypes, determined by two-sample equal variance one-tailed Student's $t$-tests, are indicated by different alphanumeric symbols $(a=0.05)$. Different letters represent significant differences. Data represent two independent experiments with 15-30 individual seedlings of each genotype.

within plant tissues to establish basic plant architecture by regulating cell division, cell fate, and pattern formation. Recent insights into the molecular mechanisms regulating auxin transport were provided by studies using auxin transport inhibitors, transport mutants, and reporter genes. These studies established a key role for the auxin-inducible auxin efflux carrier proteins (PINs) and PIN gene transcription regulators (PLTs) in controlling auxin flux to maintain an auxin maximum at the root tip (Sabatini et al. 1999; Friml et al. 2002, 2003; Aida et al. 2004; Blilou et al. 2005). Much still remains to be uncovered regarding other aspects of auxin physiology including synthesis, degradation, and conjugation.

GH3.9 (At2g47750) belongs to the 20-member A. thaliana GH3 gene family. Some GH3 family members have been shown to encode proteins that can adenylate and conjugate plant hormones to amino acids in vitro (Staswick et al. 2002, 2005; Staswick and Tiryaki 2004). One of the two Group I GH3 gene family members, JAR1/ 
FIN219/GH3.11, functions as a JA (jasmonic acid)amido synthetase to activate JA (Staswick and Tiryaki 2004), and all eight Group II-family members with the exception of GH3.9 (due to low recombinant GST protein levels) can function as indole-3-acetic acid (IAA)amido synthetases in vitro (Staswick et al. 2005). A similar function has been proposed for GH3.9, because it is capable of adenylating auxin in vitro (Staswick et al. 2002). In contrast to MeJA, which is activated by amino acid conjugation, amino acid-conjugated forms of IAA appear to be inactive. Consistent with the hypothesis of Staswick et al. that Group II GH3 members conjugate IAA to amino acids to reduce the availability of free (active) auxin, reduction-of-function mutations in some of these genes result in increased sensitivity to IAA-mediated root growth inhibition (Staswick et al. 2005), and a gain-of-function mutation in one of these genes confers resistance to IAA-mediated root growth inhibition (Nakazawa et al. 2001).

We discovered the gh3.9-1 mutant in a screen of activation tagged populations for fumonisin B1-resistant $(f b r)$ mutants (Stone et al. 2000). The original mutant had both the fbr phenotype and long primary roots. Individual F2 progeny from a backcross of gh3.9-1 to wild type were identified that retained the $f b r$ phenotype, but lacked the T-DNA insertion. Therefore, we concluded that the $f b r$ phenotype was unlinked to the T-DNA insertion, but the long-root phenotype was linked and segregated as a single recessive trait. Contrary to our expectation that the adjacent pSKI015-derived activation tagging T-DNA would bestow a dominant phenotype, the gh3.9-1 mutant identified in our study appears to be a loss-of- or reduction-of-function allele, unlike the dominant activation tagged mutations identified for the GH3 Group II family members YDK1 (GH3.2) and DFL1 (GH3.6). GH3.9-related T-DNA insertion alleles and RNAi lines with reduced GH3.9 expression also displayed the long-root phenotype. Lateral root numbers were unaffected in the gh3.9-1 mutant, consistent with published reports for mutations in other closely related gene family members (Staswick et al. 2005).

GH3 family members share high sequence similarity and may have undetectable or subtle phenotypes when mutated due to functional redundancy. However, some GH3 genes have been uncovered in mutant screens. For example, mutations in the Group I GH3.11/ JAR1/FIN219 gene, which encodes a JA-amido synthetase, are pleotropic, although there is allelic variability. GH3.11 mutations confer resistance to MeJA-mediated root growth inhibition, suppress the constitutive photomorphogenesis phenotype of a cop 1 mutant, and display a long-hypocotyl phenotype in far-red light (Staswick et al. 1992, 2002; Hsieh et al. 2000).
An activation tagged dominant mutation in Group II YDK1/GH3.2 identified in a mutant screen for altered hypocotyl elongation also had short primary roots and reduced apical dominance, but no obvious morphological phenotypes were observed in the presumed knockout mutant (Takase et al. 2004). More comprehensive investigation, however, revealed the gh3.2-1 mutant to be moderately sensitive to auxin-mediated root growth inhibition (Staswick et al. 2005). Likewise, gh3.1-1, gh3.17-1, and gh3.5-1 mutants had normal plant architecture, wild-type root growth rates, but showed increased IAA sensitivity (Staswick et al. 2005). Therefore, the gh3.9-1 mutant shares the normal leaf, shoot, or flower morphology and IAA sensitivity phenotype with several Group II loss-of-function mutants (Figure 5). In contrast, the homozygous gh3.9-1 T-DNA insertion line and the GH3.9 RNAi lines with reduced GH3.9 expression had a long-root phenotype (Figure 4), which was not seen in $g h 3.1-1, g h 3.2-1$, gh3.17-1, and gh3.5-1 loss-of-function mutants, nor the gain-offunction $d f l 1-D$ mutant (Nakazawa et al. 2001; Staswick et al. 2005). The failure to observe a root length phenotype in these mutants suggests that GH3.9 serves a distinct function in roots. The opposite root length phenotypes in the dominant $y d k 1-D$ and the recessive gh3.9-1 suggest that these two GH3 genes may have overlapping functions or expression patterns.

In primary literature and publicly available microarray gene expression databases, six of the eight Group II GH3 genes, GH3.1, YDK1 (GH3.2), GH3.3, GH3.4, GH3.5 (AtGH3a), and DFL1 (GH3.6), were reported to be induced by exogenous (and presumably endogenous) auxin (Nakazawa et al. 2001; Tanaka et al. 2002; Goda et al. 2004; Takase et al. 2004; Staswick et al. 2005). However, the two closely related Group II GH3 genes, GH3.9, and GH3.17, do not appear to be auxin responsive (Staswick et al. 2005). We investigated whether steady-state GH3.9 transcript levels were altered in seedlings treated with exogenous IAA and found that GH3.9 was downregulated by exposure to low, physiological concentrations of IAA (Figure 2a) (Ostin et al. 1998). Our results are consistent with publicly available microarray gene expression data indicating that GH3.9 is repressed by exogenous IAA (Genevestigator; http://www.genevestigator.ethz.ch/ ). Moreover, phylogenetic analyses indicate that AtGH3.9 and rice OsGH3.11 are orthologues, and OsGH3.11 expression was also unaffected or repressed by exogenous auxin (Jain et al. 2006; Terol et al. 2006).

Repression by low auxin concentrations was somewhat surprising, because the GH3.9 upstream region contains cis regulatory elements that confer auxin responsiveness: the auxin-response element (AuxRE: TGTCTC) and SAUR element (CATATG) (Figure 1b). 
However, AuxREs function in auxin response when they are adjacent to a constitutive or coupling element to create composite AuxRE elements (Guilfoyle et al. 1998), and similar sequences were not detected in the GH3.9 promoter region. ARFs (auxin-response factors) bound to AuxREs interact with Aux/IAA repressor proteins to keep auxin-responsive genes silenced when auxin concentrations are low (Tian et al. 2004; Tiwari et al. 2004). Some of these ARFs have been shown to be posttranscriptionally cleaved by microRNAs to release repression of certain GH3 genes (Mallory et al. 2005). The ARFs that might bind to the GH3.9 promoter are not known. Perhaps, they are not targets of these miRNAs, or the miRNAs that target them do not accumulate in response to auxin.

Some evidence exists that Group I GH3.11/JAR1/ FIN219 (which functions in JA conjugation) is induced by auxin (Hsieh et al. 2000). Cross talk between the signal transduction pathways regulated by various plant hormones, such as auxins and jasmonates, is further exemplified by the identification of an auxin resistance 1 (axr1) allele in a mutant screen for MeJA resistance (Tiryaki and Staswick 2002). Because we observed short roots in the MeJA-resistant jar1-1 mutant (Figure 4), we also tested gh3.9-1 for sensitivity to MeJA. We found that gh3.9-1 and the GH3.9 RNAi lines displayed moderate resistance to MeJA compared to the control jar1-1 (Figure 5). Because several GH3 genes are apparently repressed by MeJA (Genevestigator; http://www. genevestigator.ethz.ch/ ), it would be interesting to determine whether other loss-of-function mutants have jasmonate-related phenotypes.

The lack of observable phenotype in tissues other than roots is likely due to tissue- and developmentspecific expression of GH3.9 and other Group II family members. YDK1/GH3.2 that influences both hypocotyl elongation and root development is expressed primarily in flowers and roots (Takase et al. 2004). Whereas the Northern blot was informative (Figure 2b), the GH3.9 promoter::GUS reporter construct provides a more detailed picture. For example, the dominant expression in siliques can primarily be attributed to expression in the mature embryos (Figure $3 b, c)$. The relatively low expression in other tissues is due to very specific tissue localization.

Relating the observed expression patterns with respect to auxin and root physiology offers some clues as to the function of GH3.9 and the long-root phenotype. Free auxin levels are typically monitored by reporter genes driven by multimerized auxin-responsive elements (DR5::GUS or DR5::GFP). The GH3.9 promoter::GUS expression patterns tend to be oppo- site of those observed with these reporters. For example, high free auxin levels are found at the tips of cotyledons and roots of mature embryos, the base of trichomes, vasculature and hydathodes of leaves, the primary root apex and emerging lateral roots (Sabatini et al. 1999; Friml et al. 2002, 2003; Aloni et al. 2003; Ottenschlager et al. 2003; Lin and Wang 2005). Our GH3.9 promoter::GUS expression is most evident in areas with low free auxin, which might be explained by a combination of factors - the repression of GH3.9 by physiological concentrations of auxin and the presumed function of the protein in conjugating free auxin. GH3.9 promoter-driven expression was present in the proximal region of the root where cell elongation and expansion takes place, but noticeably absent in the root apex where active cell division occurs, free auxin is maximum, and auxin-inducible genes predominate (Figure $3 \mathrm{~d}$ ). This pattern of expression in roots is consistent with the pattern of auxin-related (not necessarily auxinresponsive) gene transcript accumulation determined by microarray-based transcriptome analyzes (Birnbaum et al. 2003). Root elongation rates in the gh3.9-1 mutant and RNAi lines are similar to wild-type seedlings in the early stages of root growth and become accelerated with time (Figure $4 \mathrm{a}$, Table 2). These results are in agreement with GH3.9 functioning in cells undergoing elongation, where the GH3.9 promoter is active, as opposed to in cells that are actively dividing. Exogenous IAA repressed GH3.9 expression in the cell elongation and expansion zone and triggered lateral root tip expression, a major perturbation in root auxin homeostasis in lateral roots. Perhaps, the efflux proteins are redistributing auxin in an attempt to maintain appropriate levels at the root tip.

While much has been learned about GH3 gene family function since the discovery of the enzymatic activity associated with these proteins, much remains to be learned regarding the individual roles of these proteins in plant development. For example, the phenotypic variability observed in loss-of-function mutants suggests that we still need to explore how each gene is connected to other hormone pathways involved in plant developmental processes.

It is intriguing that GH3.9 is not induced by auxin like other family members, and loss-of-function mutants exhibit only moderate IAA sensitivity. The long primary root phenotype and the moderate MeJA resistance have not been reported for mutations in any other family members. This indicates that whereas GH3.9 shares some of the features of its family members and might be acting in pathways common to other GH3 genes, it clearly has a divergent role in root development. 
Acknowledgments - Vector pFGC5941 was kindly provided by Rich Jorgenson (University of Arizona, Tucson, AZ). We would like to thank Paul Staswick, Jane Murfett, John Markwell and members of the Stone laboratory for critical discussions and review of the manuscript. We thank Christian Elowsky for his superb help with the microscopy/photography. This work was supported in part by a National Science Foundation grant to JMS (NSF IBN\#0221925). A contribution of the University of Nebraska, Agricultural Research Division, Lincoln, NE 68583.

\section{References}

Aida M, Beis D, Heidstra R, Willemsen V, Blilou I, Galinha C, Nussaume L, Noh YS, Amasino R, Scheres B (2004) The PLETHORA genes mediate patterning of the Arabidopsis root stem cell niche. Cell 119:109-120

Aloni R, Schwalm K, Langhans M, Ullrich CI (2003) Gradual shifts in sites of free-auxin production during leaf-primordium development and their role in vascular differentiation and leaf morphogenesis in Arabidopsis. Planta 216:841-853

Alonso JM, Stepanova AN, Leisse TJ, Kim CJ, Chen H, Shinn $\mathrm{P}$, Stevenson DK, Zimmerman J, Barajas P, Cheuk R, Gadrinab C, Heller C, Jeske A, Koesema E, Meyers CC, Parker H, Prednis L, Ansari Y, Choy N, Deen H, Geralt M, Hazari N, Hom E, Karnes M, Mulholland C, Ndubaku R, Schmidt I, Guzman P, Aguilar-Henonin L, Schmid M, Weigel D, Carter DE, Marchand T, Risseeuw E, Brogden D, Zeko A, Crosby WL, Berry CC, Ecker JR (2003) Genomewide insertional mutagenesis of Arabidopsis thaliana. Science 301:653-657

Ausubel FM, Brent R, Kingston RE, Moore DD, Seidman JG, Smith JA, Struhl K (eds) (2006) Current Protocols in Molecular Biology. Wiley, New York

Birnbaum K, Shasha DE, Wang JY, Jung JW, Lambert GM, Galbraith DW, Benfey PN (2003) A gene expression map of the Arabidopsis root. Science 302:1956-1960

Blilou I, Xu J, Wildwater M, Willemsen V, Paponov I, Friml J, Heidstra R, Aida M, Palme K, Scheres B (2005) The PIN auxin efflux facilitator network controls growth and patterning in Arabidopsis roots. Nature 433:39-44

Clough SJ, Bent AF (1998) Floral dip: a simplified method for Agrobacterium-mediated transformation of Arabidopsis thaliana. Plant J 16:735-743

Dellaporta SL, Wood J, Hicks JB (1983) A plant DNA minipreparation: version II. Plant Mol Biol Rep 1:19-21

Downing WL, Mauxion F, Fauvarque MO, Reviron MP, de Vienne D, Vartanian N, Giraudat J (1992) A Brassica napus transcript encoding a protein related to the Kunitz protease inhibitor family accumulates upon water stress in leaves, not in seeds. Plant J 2:685-693

Friml J, Benkova E, Blilou I, Wisniewska J, Hamann T, Ljung K, Woody S, Sandberg G, Scheres B, Jurgens G, Palme K (2002) AtPIN4 mediates sink-driven auxin gradients and root patterning in Arabidopsis. Cell 108:661-673
Friml J, Vieten A, Sauer M, Weijers D, Schwarz H, Hamann T, Offringa R, Jurgens G (2003) Efflux-dependent auxin gradients establish the apical-basal axis of Arabidopsis. Nature 426:147-153

Goda H, Sawa S, Asami T, Fujioka S, Shimada Y, Yoshida S (2004) Comprehensive comparison of auxin-regulated and brassinosteroid-regulated genes in Arabidopsis. Plant Physiol 134:1555-1573

Guilfoyle TJ, Ulmasov T, Hagen G (1998) The ARF family of transcription factors and their role in plant hormone-responsive transcription. Cell Mol Life Sci 54:619-627

Hagen G, Guilfoyle T (2002) Auxin-responsive gene expression: genes, promoters and regulatory factors. Plant Mol Biol 49:373-385

Hagen G, Guilfoyle TJ (1985) Rapid induction of selective transcription by auxins. Mol Cell Biol 5:1197-1203

Hagen G, Martin G, Li Y, Guilfoyle TJ (1991) Auxin-induced expression of the soybean GH3 promoter in transgenic tobacco plants. Plant Mol Biol 17:567-579

Higo K, Ugawa Y, Iwamoto M, Korenaga T (1999) Plant cisacting regulatory DNA elements (PLACE) database: 1999. Nucleic Acids Res 27:297-300

Hsieh HL, Okamoto H, Wang M, Ang LH, Matsui M, Goodman H, Deng XW (2000) FIN219, an auxin-regulated gene, defines a link between phytochrome A and the downstream regulator COP1 in light control of Arabidopsis development. Genes Dev 14:1958-1970

Jain M, Kaur N, Tyagi AK, Khurana JP (2006) The auxin-responsive GH3 gene family in rice (Oryza sativa). Funct Integr Genomics 6:36-46

Jefferson RA (1987) Assaying chimeric genes in plants: The GUS gene fusion system. Plant Mol Biol Rep 5:387-405

Lin R, Wang H (2005) Two homologous ATP-binding cassette transporter proteins, AtMDR1 and AtPGP1, regulate Arabidopsis photomorphogenesis and root development by mediating polar auxin transport. Plant Physiol 138:949-964

Liscum E, Reed JW (2002) Genetics of Aux/IAA and ARF action in plant growth and development. Plant Mol Biol 49:387-400

Mallory AC, Bartel DP, Bartel B (2005) MicroRNA-directed regulation of Arabidopsis AUXIN RESPONSE FACTOR17 is essential for proper development and modulates expression of early auxin response genes. Plant Cell 17:1360-1375

Medberry SL, Dale E, Qin M, Ow DW (1995) Intra-chromosomal rearrangements generated by Cre-lox site-specific recombination. Nucleic Acids Res 23:485-490

Nakazawa M, Yabe N, Ichikawa T, Yamamoto YY, Yoshizumi T, Hasunuma K, Matsui M (2001) DFL1, an auxin-responsive GH3 gene homologue, negatively regulates shoot cell elongation and lateral root formation, and positively regulates the light response of hypocotyl length. Plant J 25:213-221

Normanly J, Bartel B (1999) Redundancy as a way of life - IAA metabolism. Curr Opin Plant Biol 2:207-213 
Ostin A, Kowalyczk M, Bhalerao RP, Sandberg G (1998) Metabolism of indole-3-acetic acid in Arabidopsis. Plant Physiol 118:285-296

Ottenschlager I, Wolff P, Wolverton C, Bhalerao RP, Sandberg G, Ishikawa H, Evans M, Palme K (2003) Gravity-regulated differential auxin transport from columella to lateral root cap cells. Proc Natl Acad Sci USA 100:2987-2991

Sabatini S, Beis D, Wolkenfelt H, Murfett J, Guilfoyle T, Malamy J, Benfey P, Leyser O, Bechtold N, Weisbeek P, Scheres B (1999) An auxin-dependent distal organizer of pattern and polarity in the Arabidopsis root. Cell 99:463-472

Staswick PE, Serban B, Rowe M, Tiryaki I, Maldonado MT, Maldonado MC, Suza W (2005) Characterization of an Arabidopsis enzyme family that conjugates amino acids to indole-3-acetic acid. Plant Cell 17:616-627

Staswick PE, Su W, Howell SH (1992) Methyl jasmonate inhibition of root growth and induction of a leaf protein are decreased in an Arabidopsis thaliana mutant. Proc Natl Acad Sci USA 89:6837-6840

Staswick PE, Tiryaki I (2004) The oxylipin signal jasmonic acid is activated by an enzyme that conjugates it to isoleucine in Arabidopsis. Plant Cell 16:2117-2127

Staswick PE, Tiryaki I, Rowe ML (2002) Jasmonate response locus JAR1 and several related Arabidopsis genes encode enzymes of the firefly luciferase superfamily that show activity on jasmonic, salicylic, and indole-3-acetic acids in an assay for adenylation. Plant Cell 14:1405-1415

Stone JM, Heard JE, Asai T, Ausubel FM (2000) Simulation of fungal-mediated cell death by fumonisin B1 and selection of fumonisin B1-resistant (fbr) Arabidopsis mutants. Plant Cell 12:1811-1822

Takase T, Nakazawa M, Ishikawa A, Kawashima M, Ichikawa T, Takahashi N, Shimada H, Manabe K, Matsui M (2004) $y d k 1-D$, an auxin-responsive GH3 mutant that is involved in hypocotyl and root elongation. Plant J 37:471-483

Takase T, Nakazawa M, Ishikawa A, Manabe K, Matsui M (2003) DFL2, a new member of the Arabidopsis GH3 gene family, is involved in red light-specific hypocotyl elongation. Plant Cell Physiol 44:1071-1080

Tanaka S, Mochizuki N, Nagatani A (2002) Expression of the AtGH3a gene, an Arabidopsis homologue of the soybean $\mathrm{GH} 3$ gene, is regulated by phytochrome B. Plant Cell Physiol 43:281-289
Terol J, Domingo C, Talon M (2006) The GH3 family in plants: Genome wide analysis in rice and evolutionary history based on EST analysis. Gene 371:279-290

Tian CE, Muto H, Higuchi K, Matamura T, Tatematsu K, Koshiba T, Yamamoto KT (2004) Disruption and overexpression of auxin response factor 8 gene of Arabidopsis affect hypocotyl elongation and root growth habit, indicating its possible involvement in auxin homeostasis in light condition. Plant J 40:333-343

Tiryaki I, Staswick PE (2002) An Arabidopsis mutant defective in jasmonate response is allelic to the auxin-signaling mutant axr1. Plant Physiol 130:887-894

Tiwari SB, Hagen G, Guilfoyle TJ (2004) Aux/IAA proteins contain a potent transcriptional repression domain. Plant Cell 16:533-543

Toufighi K, Brady SM, Austin R, Ly E, Provart NJ (2005) The Botany Array Resource: e-Northerns, Expression Angling, and promoter analyses. Plant J 43:153-163

Weigel D, Ahn JH, Blazquez MA, Borevitz JO, Christensen SK, Fankhauser C, Ferrandiz C, Kardailsky I, Malancharuvil EJ, Neff MM, Nguyen JT, Sato S, Wang ZY, Xia Y, Dixon RA, Harrison MJ, Lamb CJ, Yanofsky MF, Chory J (2000) Activation tagging in Arabidopsis. Plant Physiol 122:1003-1013

Wesley SV, Helliwell CA, Smith NA, Wang MB, Rouse DT, Liu Q, Gooding PS, Singh SP, Abbott D, Stoutjesdijk PA, Robinson SP, Gleave AP, Green AG, Waterhouse PM (2001) Construct design for efficient, effective and high-throughput gene silencing in plants. Plant J 27:581-590

Woodward AW, Bartel B (2005) Auxin: regulation, action, and interaction. Ann Bot (Lond) 95:707-735

Zhou YX, Newton RJ, Gould JH (1997) A simple method for identifying plant/T-DNA junction sequences resulting from Agrobacterium-mediated DNA transformation. Plant Mol Biol Rep 15:246-254

Zimmermann P, Hirsch-Hoffmann M, Hennig L, Gruissem W (2004) Genevestigator. Arabidopsis microarray database and analysis toolbox. Plant Physiol 136:2621-2632 